\title{
Characterization of the Bacterial Community Associated with Larvae and Adults of Anoplophora chinensis Collected in Italy by Culture and Culture-Independent Methods
}

\author{
Aurora Rizzi, ${ }^{1}$ Elena Crotti, ${ }^{1}$ Luigimaria Borruso, ${ }^{1,2}$ Costanza Jucker, ${ }^{1}$ Daniela Lupi, ${ }^{1}$ \\ Mario Colombo, ${ }^{1}$ and Daniele Daffonchio ${ }^{1}$ \\ ${ }^{1}$ Department of Food, Environmental and Nutritional Sciences (DEFENS), University of Milan, Via Celoria 2, 20133 Milan, Italy \\ ${ }^{2}$ Faculty of Science and Technology, Free University of Bozen-Bolzano, Piazza Università 5, 39100 Bolzano, Italy
}

Correspondence should be addressed to Daniele Daffonchio; daniele.daffonchio@unimi.it

Received 16 April 2013; Accepted 9 July 2013

Academic Editor: George Tsiamis

Copyright (C) 2013 Aurora Rizzi et al. This is an open access article distributed under the Creative Commons Attribution License, which permits unrestricted use, distribution, and reproduction in any medium, provided the original work is properly cited.

\begin{abstract}
The wood-boring beetle Anoplophora chinensis Forster, native to China, has recently spread to North America and Europe causing serious damage to ornamental and forest trees. The gut microbial community associated with these xylophagous beetles is of interest for potential biotechnological applications in lignocellulose degradation and development of pest-control measures. In this study the gut bacterial community of larvae and adults of A. chinensis, collected from different host trees in North Italy, was investigated by both culture and culture-independent methods. Larvae and adults harboured a moderately diverse bacterial community, dominated by Proteobacteria, Actinobacteria, and Firmicutes. The gammaproteobacterial family Enterobacteriaceae (genera Gibbsiella, Enterobacter, Raoultella, and Klebsiella) was the best represented. The abundance of such bacteria in the insect gut is likely due to the various metabolic abilities of Enterobacteriaceae, including fermentation of carbohydrates derived from lignocellulose degradation and contribution to nitrogen intake by nitrogen-fixing activity. In addition, bacteria previously shown to have some lignocellulose-degrading activity were detected at a relatively low level in the gut. These bacteria possibly act synergistically with endogenous and fungal enzymes in lignocellulose breakdown. The detection of actinobacterial symbionts could be explained by a possible role in the detoxification of secondary plant metabolites and/or protection against pathogens.
\end{abstract}

\section{Introduction}

Insects have complex associations with a wide variety of microorganisms. Many bacteria contribute to various physiological functions, including nutrition, development, reproduction, resistance to pathogens, production of pheromones, and immunity [1]. Some symbionts can play essential roles in the insect gut, compensating for diets deficient in certain nutrients or containing recalcitrant organic compounds. For instance, in xylophagous termites the gut microflora enables the host to digest cellulose and fix atmospheric nitrogen $[2,3]$, and in phytophagous aphids the endocellular symbiont Buchnera aphidicola synthesizes essential amino acids that are absent in phloem sap $[4,5]$. These gut-microbe interactions are diverse and include antagonism, commensalism, and mutualism and range from obligate to facultative [6]. Obligate symbiotic microorganisms are typically vertically transmitted during early stages of oogenesis or embryogenesis, whereas facultative symbionts can colonize native hosts through horizontal transmission between individuals or acquisition from the diet or the environment [7-11]. All these properties and the important roles that symbionts have in host biology have been proposed for exploitation in novel control strategies of insect pests or for the management of insect-related problems [12-14].

The longhorned beetles (Coleoptera: Cerambycidae) are xylophagous insects which feed on healthy or dead woody plants causing damage of forest and ornamental trees. Many beetles establish a strict association with fungi that naturally colonize their galleries and provide nutrients by lignocellulose degradation and synthesis of other essentials compounds. The genus Anoplophora includes xylophagous 
longhorned beetles, native to eastern Asia, that live on numerous woody plant species. Since its accidental introduction through wood-packing materials and live plants from Asia, it has become an important invasive pest both in Europe and North America. In the United States, the species $A$. glabripennis is spread, whereas in Europe the species $A$. chinensis, form malasiaca, is mostly present $[15,16]$. The lifecycle of $A$. chinensis lasts 12-24 months, and larvae develop by feeding on cambium, phloem, and subsequently xylem, forming tunnels into the inner bark of the tree and causing death of the host. Oviposition occurs in the bark of the host tree, and eggs, larvae, and pupae can overwinter. In late spring adults emerge and feed on the bark of tender twigs.

Due to their specific diet, comprising highly lignified lownitrogen wood tissues, gut symbionts may play important roles in the digestive tract of these xylophagous insects, contributing to lignocellulose degradation and synthesis of essential amino acids or vitamins [17]. Studies conducted on larvae of A. glabripennis collected in USA and China documented the wide diversity of bacterial taxa harboured in larval guts $[18,19]$. The bacterial communities of animals reared on different host trees were extremely variable, with a significant impact on cellulase activity [18]. Larval guts of $A$. glabripennis were also found to be associated with the softrot fungus Fusarium solani, capable of degrading proteins, cellulose, hemicelluloses, and other woody carbohydrate polymers [20]. However, the recent discovery of an endogenous exocellulase from $A$. malasiaca [21] raises the question of the contribution of gut microorganisms to lignocellulose degradation and, more extensively, their contribution to the beetle's physiology and biochemistry. Further research to characterize the microbial communities of related species, investigating the variation in communities in relation to geography and/or different life stages, could contribute to a better understanding of the complex symbiotic relationships of beetles with microorganisms and the impact of microorganisms on the host lifecycle.

The aim of this study was to investigate the bacterial community associated with both larvae and adults of $A$. chinensis, collected in Italy, using both culture-dependent and independent methods, namely, PCR-DGGE (denaturant gradient gel electrophoresis) and clone library analysis.

\section{Materials and Methods}

2.1. Insect Collection and Dissection. Larvae and adults of A. chinensis were collected from April to November 2008 at different sites within the infested area in Lombardy, Italy (Table 1). After collection, larvae and adults were maintained separately in sterile containers at $10^{\circ} \mathrm{C}$ and processed the following day. The insects were surface disinfected with $60 \%$ ethanol and rinsed twice in sterile water. Each larva was dissected near a Bunsen burner using sterilized dissection scissors, and the entire gut was extracted from the insect body. The same procedure was followed for adult individuals; in addition, male gonads, and eggs inside the female abdomen were also extracted. The individual guts, gonads and eggs were washed in $4 \mathrm{~mL}$ of sterile water, transferred to $1.5 \mathrm{~mL}$
TABLE 1: Anoplophora chinensis collection and detection strategies used in this study.

\begin{tabular}{lcc}
\hline Host tree & Insects (no.) & $\begin{array}{c}\text { Detection } \\
\text { strategies }\end{array}$ \\
\hline Alnus & Larvae (9) & $\begin{array}{c}\text { Isolation and } \\
\text { library clones } \\
\text { (pool of 2 guts) }\end{array}$ \\
$\begin{array}{l}\text { Liquidambar } \\
\text { Salix caprea }\end{array}$ & Larvae (8) & DGGE \\
Acer & Larvae (10) & DGGE \\
saccharinum & Adults (3) & Isolation and \\
& & DGGE \\
Alnus & Adults (2) & $\begin{array}{c}\text { Isolation, library } \\
\text { clones (pool of 2 } \\
\text { guts), and }\end{array}$ \\
& & DGGE \\
\hline
\end{tabular}

tubes with $500 \mu \mathrm{L}$ of saline, and homogenized using a sterile plastic pestle. Homogenates were used for cultureindependent methods and stored at $-20^{\circ} \mathrm{C}$ until use.

2.2. Bacteria Isolation. The gut homogenates were 10 -fold diluted and directly plated on tryptic soy agar (TSA) and $1 / 10$ strength TSA (Difco, Milan, Italy). Fifty $\mu \mathrm{L}$ of gut homogenates were also used for the enrichment of nitrogenfixing bacteria in LGI liquid medium (5\% sucrose, $0.06 \%$ $\mathrm{KH}_{2} \mathrm{PO}_{4}, 0.02 \% \mathrm{~K}_{2} \mathrm{HPO}_{4}, 0.02 \% \mathrm{MgSO}_{4}, 0.002 \% \mathrm{CaCl}_{2}$, $0.001 \% \mathrm{FeCl}_{3}$, and $0.0002 \% \mathrm{NaMoO}_{4}, \mathrm{pH} 6$ [22]). After growth, the enriched cultures were plated on LGI agar plates containing $20 \mathrm{~g} / \mathrm{L}$ noble agar (Difco). All media were supplemented with $100 \mu \mathrm{g} / \mathrm{mL}$ cycloheximide. Plates were incubated for $3-5$ days at $30^{\circ} \mathrm{C}$. The colonies obtained by plating were differentiated based on morphological features including shape, colour, margins, elevation, and texture. Two or more isolates representative of each colony morphology were transferred to fresh agar plates, and pure colonies were stored at $-80^{\circ} \mathrm{C}$ in $15 \%$ glycerol.

2.3. DNA Isolation, PCR, and Cloning. Total DNA from dissected organs was isolated as previously reported [23]. DNA was extracted by enzymatic and chemical treatment and purified using the Wizard DNA purification resin (Promega, Milan, Italy). PCR amplification of the 16S rRNA gene from bacterial isolates was performed using the universal primers $27 \mathrm{~F}$ and $1492 \mathrm{R}$ [24]. The reaction mixture $(50 \mu \mathrm{L})$ contained $1 \times$ PCR buffer, $1.5 \mathrm{mM} \mathrm{MgCl}_{2}, 0.5 \mu \mathrm{M}$ of each primer, $0.2 \mathrm{mM}$ of dNTPs, and $1.5 \mathrm{U}$ of Taq DNA polymerase. The DNA template was obtained by transferring a small portion of a pure colony into a PCR tube. The thermal cycling program consisted of $5 \mathrm{~min}$ at $95^{\circ} \mathrm{C}$, followed by 30 cycles of $45 \mathrm{~s}$ at $95^{\circ} \mathrm{C}, 1 \mathrm{~min}$ at $55^{\circ} \mathrm{C}$, and $1 \mathrm{~min}$ at $72^{\circ} \mathrm{C}$, with a final extension of $10 \mathrm{~min}$ at $72^{\circ} \mathrm{C}$.

Two $16 \mathrm{~s}$ rRNA gene libraries, one from larvae and one from adults, were constructed using two pooled guts per each library (Table 2). The DNA isolated from the pooled guts was amplified using the primer pair $27 \mathrm{~F}$ and $1492 \mathrm{R}$, as previously described. The resulting $1.5 \mathrm{~kb}$ fragments were 


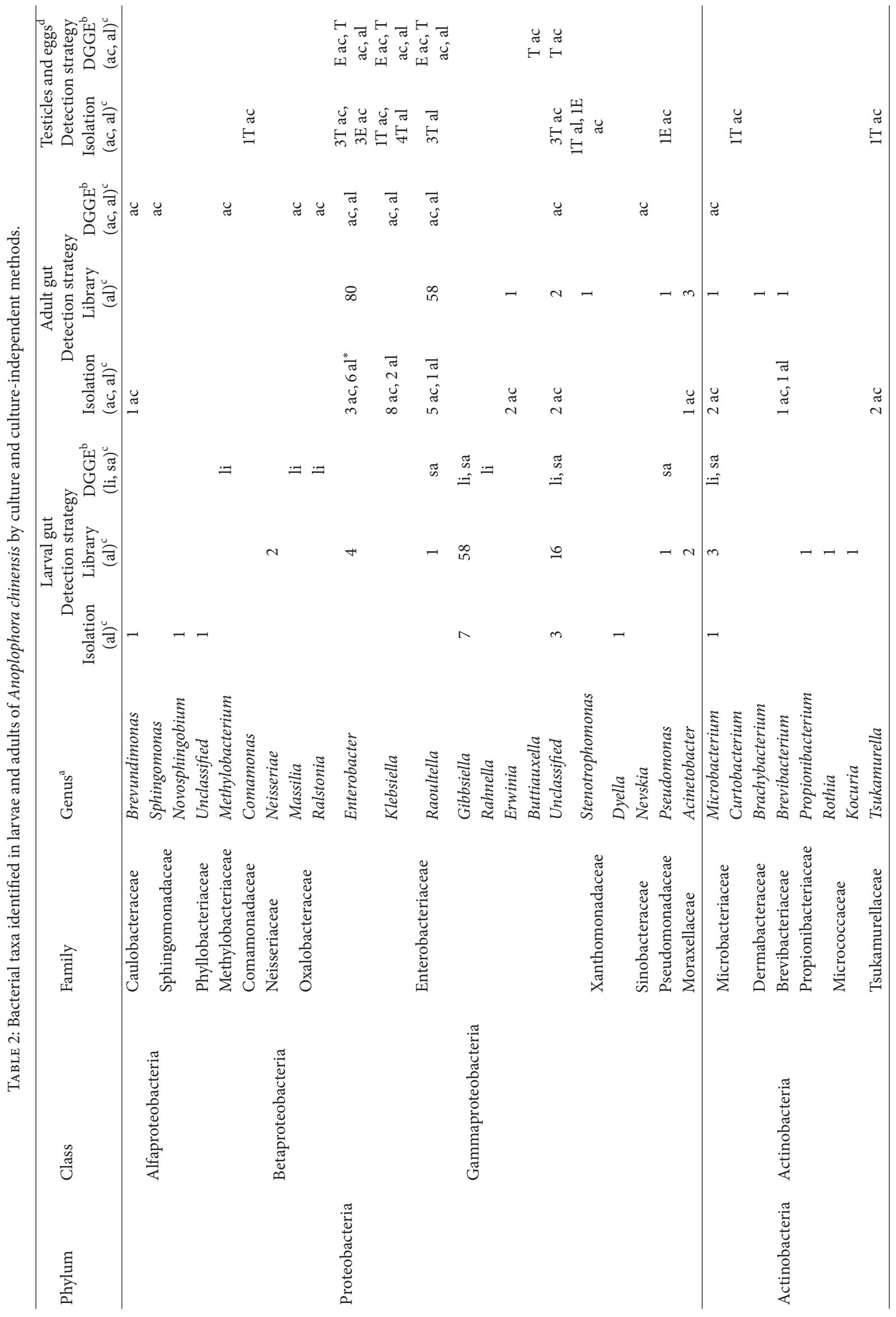




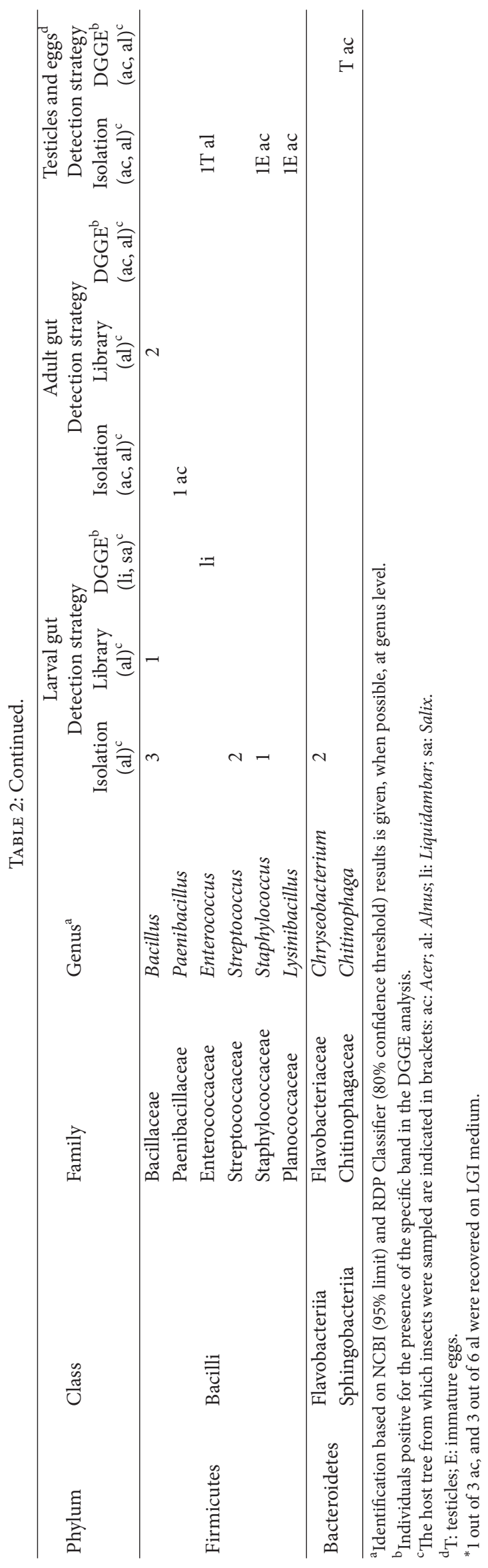


cloned into pCRII-TOPO vector (Invitrogen Life Technologies, Milan, Italy) following the manufacturer's protocol. Individual colonies were picked up using sterile pipette tips and used directly for PCR amplification. Insert DNA from $16 \mathrm{~S}$ rRNA clones was amplified by standard PCR amplification using the primers M13F/M13R [25] and sequenced.

2.4. PCR-DGGE Analysis. Bacterial 16S rRNA gene fragments were amplified by PCR using the primer pair GC-357F/907-R [26-28]. PCR reactions were performed as previously described [29]. Briefly, PCR products (approx. $300 \mathrm{ng}$ ) were loaded onto $7 \%(\mathrm{w} / \mathrm{v})$ polyacrylamide gels $(0.75 \mathrm{~mm})$ with a denaturant gradient of $40-60 \%$ (100\% denaturant contained $7 \mathrm{M}$ urea and $40 \%$ formamide). Electrophoresis was run in $1 \times$ TAE buffer using a D-Code electrophoresis system (BioRad, Milan, Italy) at $90 \mathrm{~V}$ and $60^{\circ} \mathrm{C}$ for $17 \mathrm{~h}$. Gels were stained with SYBR Green I Nucleic Acid Gel Stain (Invitrogen Life Technologies) and documented with GelDoc 2000 apparatus (BioRad) using the Diversity Database software (BioRad). Relevant DNA bands were excised from the gels and eluted in $50 \mu \mathrm{L}$ of Tris- $\mathrm{HCl} 10 \mathrm{mM}$. Five microlitres of DNA was used for 16S DNA fragment reamplification using nonclamped primers and the obtained amplicons sequenced.

2.5. Sequencing and Data Analysis. Sequencing of the $16 \mathrm{~S}$ rRNA gene fragments was performed using the primer $27 \mathrm{~F}$ at Primm (Milan, Italy). Partial sequences from clones and bacterial isolates were compared against the National Center for Biotechnology Information (NCBI) genomic database with the BLAST (http://blast.ncbi.nlm.nih.gov/Blast.cgi) search alignment tool. A collection of phylogenetically related sequences was obtained from the NCBI database. Sequences from clones were taxonomically classified by the RDP-II Naive Bayesian Classifier (http://rdp.cme.msu.edu/classifier/ classifier.jsp) using an $80 \%$ confidence threshold. Sequence alignment was carried out and phylogenetic trees constructed using MEGA software, version 5.1 [30]. The trees were constructed using the maximum likelihood algorithm and Tamura Nei parameter correction and were bootstrapped 1000 times.

\section{Results}

3.1. Bacterial Community in Larval and Adult Guts. Guts of larvae fed on Alnus were investigated by both culturing (seven individual guts) and library clones (pool of two guts). The sequences of bacterial 16S rRNA genes from 23 isolates and 91 clones were obtained. Most isolates were strictly affiliated to the Gibbsiella genus (Figure 1 and Table 2). Similarly, using library cloning, the majority of gut-derived clones were represented by the Gibbsiella genus ( $n=58,63 \%$ ) and bacteria strictly affiliated to Gibbsiella and uncultured clones previously identified in larval guts from other woodboring beetles (Agrilus planipennis, Saperda vestita, and Apriona germari). The genera Enterobacter and Raoultella were represented in low proportions (approximately 5 and $1 \%$, resp.).
In addition, PCR-DGGE analysis was used to further investigate the dominant microbial species of multiple individuals (Figure 2). The gut bacterial profiles obtained from eighteen larvae grown in Liquidambar and Salix trees differed markedly but were highly similar to larvae collected from the same site/tree (Figure 2). Sequences of dominant intense bands showing tight affiliationto Raoultella (bands 14, 15, 18-21, 23, 24) and unclassified Enterobacteriaceae (band 17) were detected in larvae from Salix, whereas sequences of faint bands, also related to unclassified Enterobacteriaceae (band 4), were found in larvae from Liquidambar. Gibbsiella (bands 12 and 16) and Rahnella (band 11) were occasionally detected, independently of the host tree.

The microbial communities of guts of five adults (four males and one female) fed on Alnus or Acer were analyzed by both culturing and culture-independent methods. The sequences of $16 \mathrm{~S}$ rRNA genes from 38 isolates, 151 clones, and 28 DGGE bands were obtained (Tables 2 and 3). Overall, the results of the different analyses indicated that the Enterobacteriaceae were the dominant bacteria also in the adult gut. In particular, DGGE analysis, in accordance with culturing, indicated that Enterobacter (bands 29, 32, 33, 46) was detected in all five individuals tested, whereas Klebsiella (25-28, 4245 ) and Raoultella (47-51) were found only in some individuals ( 3 and 1 out of 5 individuals, resp.). One adult individual presented Enterobacter (bands 32 and 33) (Figure 2) and microorganisms strictly affiliated to the genus Erwinia (Figure 1). Microorganisms affiliated to Enterobacter were also identified when performing enrichment of nitrogenfixing bacteria. Data from library cloning performed on beetles fed on Alnus (pool of two guts) indicated an abundance of Enterobacter and Raoultella in the gut microbial community, with percentages over the total sequenced clones of $52 \%$ ( $n=$ $80)$ and $38 \%(n=58)$, respectively. This result is consistent with the high intensities of the bands relative to these bacteria in DGGE gels. However, no library clones related to the genus Klebsiella were detected, maybe due to differences in PCR amplificability of DNA extracted from the two guts and/or to the different amount of template DNA in PCR reactions due to the different sizes of adult guts.

All the analytical methods used revealed a rather diverse community generally characterized by the dominance of Enterobacteriaceae in both larvae and adult stages and the occurrence of several species encompassing different taxa (Proteobacteria, Actinobacteria, Firmicutes, and Bacteroidetes). In particular, some other Gammaproteobacteria, such as Acinetobacter and Pseudomonas, were detected in larval and adult guts by culture-independent analyses. Members of Alpha- and Betaproteobacteria groups were found by DGGE and isolation methods in both larvae and adults. Interestingly, Ralstonia, Massilia, and Methylobacterium were found in all larval individuals that fed on Liquidambar. It can be speculated that the aromatic resin produced from this host tree species had an impact on the microbial composition of the larval gut communities. The gut bacterial microbiome of Anoplophora comprised additional representatives of Actinobacteria and Firmicutes. In particular, the genera Microbacterium and Bacillus were detected in both larvae and adults using the majority of methods. Some species were 

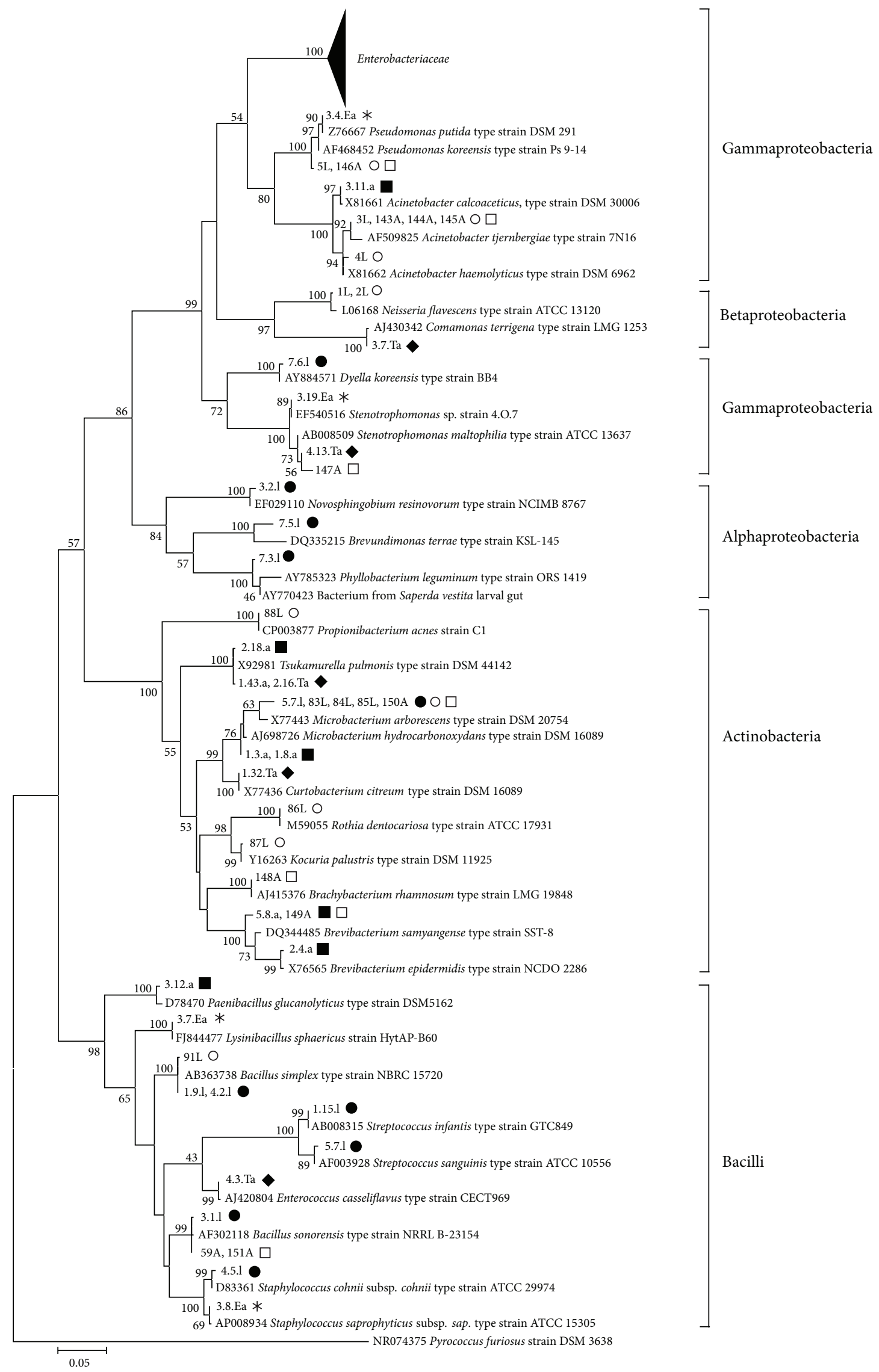

(a)

FIGURE 1: Continued. 


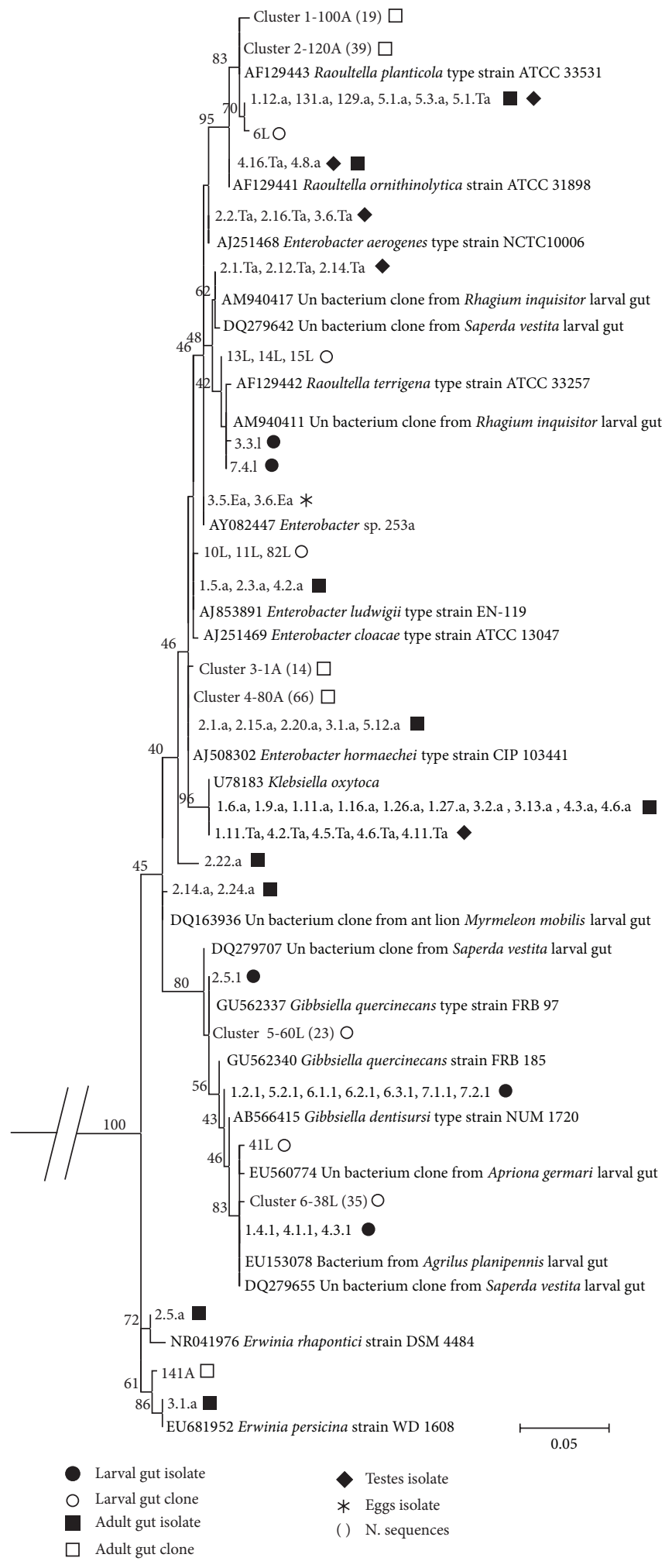

(b)

FIGURE 1: Phylogenetic tree of partial bacterial 16S rRNA sequences retrieved from culturing and clone library. Bacterial sequences fell mainly into five classes (a) and most belonged to the Enterobacteriaceae family (b). The category of origin in which each species was identified is indicated by symbols. Groups of sequences are compressed into clusters, and the number of sequences is provided in brackets. "Un" indicates an uncultured bacterium. Numbers at nodes represent bootstrap values and are indicated when values were $>40 \%$. The scale bar represents 0.05 substitutions per nucleotide position. 


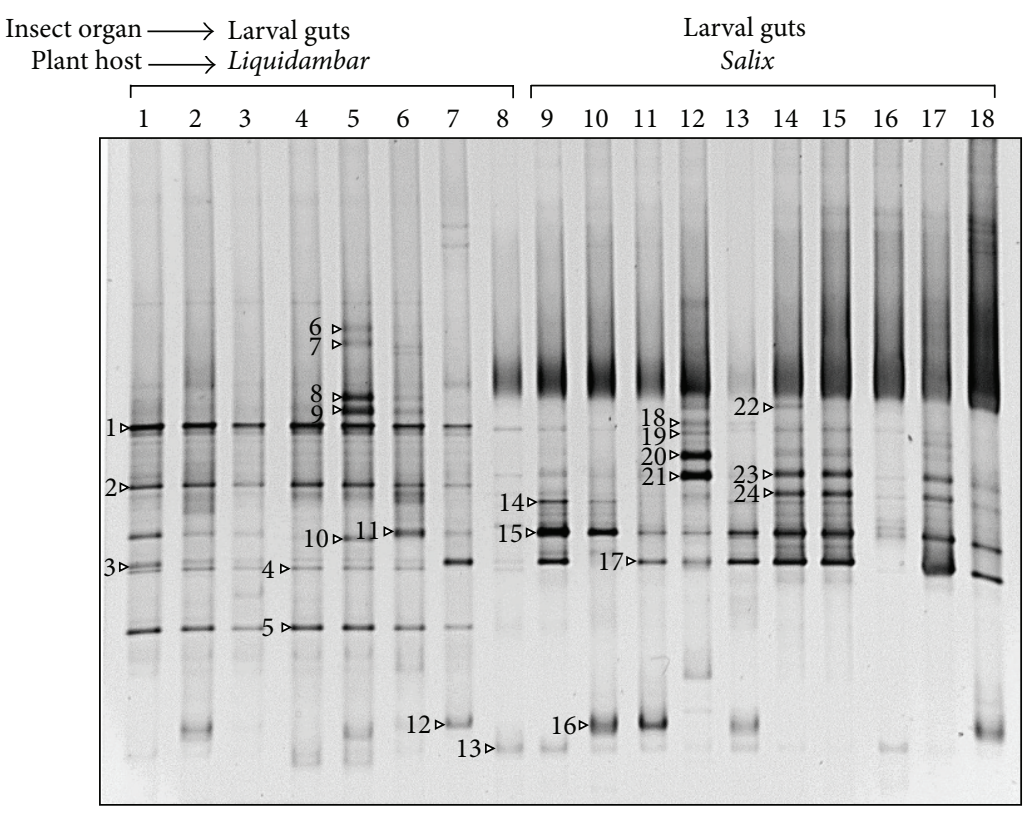

(a)

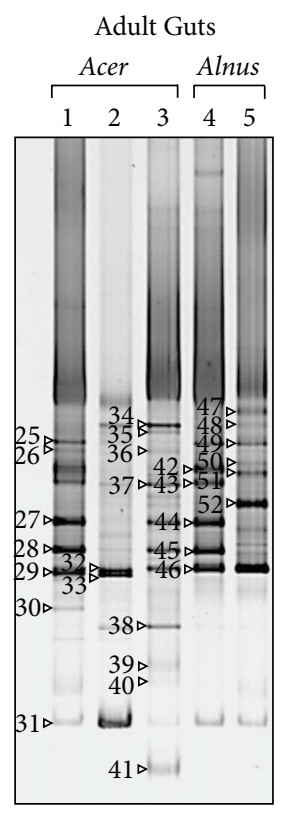

(b)

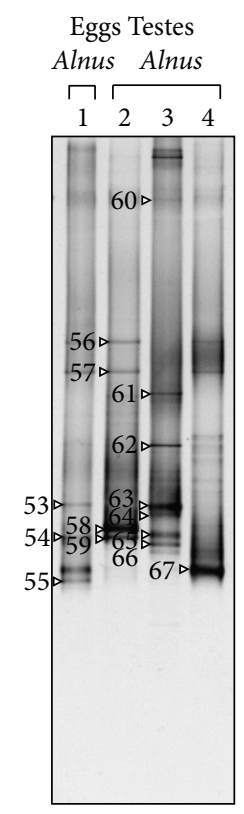

(c)

Figure 2: Bacterial DGGE profiles of the 16S rRNA gene PCR products amplified from DNA extracted from guts (a, b) and eggs and testes $(b, c)$ of larvae (a) and adults (b, c) of A. chinensis collected from different host trees. Triangles and numbers indicate the bands sequenced (Table 3).

detected occasionally in larvae or adults by culture or cultureindependent analysis. Rothia, Kocuria, Propionibacterium, Enterococcus, Streptococcus, Staphylococcus, and Chryseobacterium were found in larvae, while Brevibacterium, Tsukamurella, and Paenibacillus were found in adults.

\subsection{Bacterial Community in Adult Testicles and Immature} Eggs. Data from isolation and DGGE detection methods revealed an abundance of Enterobacteriaceae also associated with testicles and eggs (Table 2 and Figure 2). Similar to microbial gut investigation, the DGGE patterns indicated that the occurrence of diverse microbial genera (Enterobacter, Raoultella, Klebsiella, and Buttiauxella) and unclassified bacteria varied among the samples. Lysinibacillus sphaericus and Stenotrophomonas maltophilia isolates were detected in both testicles and eggs. Staphylococcus was also found in eggs, whereas other microorganisms, generally of environmental origin, were identified in testicles.

\section{Discussion}

Overall, the results indicated that the gut microbiota of larvae and adults of Anoplophora chinensis was relatively complex being constituted by bacteria placed in six different bacterial classes. A total of 23 and 32 bacterial genera were found in larvae and adults (19 in the gut), respectively, by both culturedependent and independent methods. This moderately high diversity is in accordance with previous data reported for larval forms of the species Anoplophora glabripennis [18, 19]. Twenty-three bacterial taxa were harboured in the larval gut of A. glabripennis from China, and a range of 5-31 genera, depending on the host tree, were found in the larval gut of field-collected A. glabripennis from USA. The bacterial communities, especially in the case of larvae, showed significant differences as a function of host tree, site of sampling, and, to a lesser extent, specific individuals. The influence of host tree was particularly evident in the case of larvae. Consistent with previous results, the complexity of the bacterial community was higher in larvae fed on the host trees preferred by the insects, which in this study were Acer and Salix. In addition, we observed that larvae from these trees contained a higher proportion of Enterobacteriaceae. According to Geib et al. [18], the plasticity that characterizes the Anoplophora bacterial community is probably the reason for the broad host range of this beetle. However, regardless of differences in the insect species analyzed and geographic location of sampling (USA, China, Italy), the bacterial communities found in studies of the larvae of Anoplophora spp. are quite similar. Interestingly, the studies investigating the taxonomy and diet of bark-beetles related to Anoplophora spp. found the majority of these xylophagous insects to have a lower bacterial diversity than Anoplophora spp., ranging from four taxa identified in Tetropium castaneum [31] to an average of about ten taxa in Dendroctonus species [32-35]. The toxic activity of certain tree chemicals, such as terpenes in pine resin, may be one of the factors determining the relatively scarce species diversity in the gut of these beetles with respect to Anoplophora.

In this study, for the first time we showed that the bacterial community was rather conserved also in adults regardless of the shift in diet occurring after the metamorphosis, with 
TABLE 3: Closest relatives of bacterial 16S rRNA gene sequences of DGGE bands obtained from larvae and adults of Anoplophora chinensis.

\begin{tabular}{|c|c|c|c|}
\hline Band & Closest relative (accession no.) & Identity $(\%)$ & Bacterial division \\
\hline 1 & Ralstonia solanacearum (JQ655458) & 100 & Betaproteobacteria \\
\hline 34 & Ralstonia sp. (JN714979) & $99.1-99.7$ & Betaproteobacteria \\
\hline 2 & Uncultured Massilia sp. (EF075289) & 99.3 & Betaproteobacteria \\
\hline 35 & Uncultured Massilia sp. (JN648276) & 99.3 & Betaproteobacteria \\
\hline 37 & Massilia sp. (AB623119) & 98.4 & Betaproteobacteria \\
\hline \multirow{2}{*}{3,17} & Raoultella terrigena (AY292875) & 100 & Gammaproteobacteria \\
\hline & Enterobacter sp. (AB673457) & $99.2-99.6$ & Gammaproteobacteria \\
\hline \multirow{2}{*}{$14,15,23,24$} & Uncultured Raoultella sp. (FJ467399) & $99.2-99.8$ & Gammaproteobacteria \\
\hline & Raoultella terrigena (JN815233) & $99.0-99.6$ & Gammaproteobacteria \\
\hline $18,19,20,21$ & Raoultella ornithinolytica (HE578796) & $98.4-99.8$ & Gammaproteobacteria \\
\hline $47,48,49,50,51$ & Raoultella planticola (JN835545) & $99.2-99.6$ & Gammaproteobacteria \\
\hline 52 & Raoultella ornithinolytica (HQ242732) & 98.4 & Gammaproteobacteria \\
\hline 53 & Raoultella planticola (HE610795) & 99.6 & Gammaproteobacteria \\
\hline 56 & Uncultured Raoultella sp. (FJ467399) & 99.6 & Gammaproteobacteria \\
\hline 58 & Raoultella terrigena (GQ169108) & 100 & Gammaproteobacteria \\
\hline 62 & Raoultella ornithinolytica (HQ242729) & 99.8 & Gammaproteobacteria \\
\hline 10 & Gammaproteobacterium (EF111244) & 99.8 & Gammaproteobacteria \\
\hline 11 & Rahnella sp. (JQ864392) & 99.7 & Gammaproteobacteria \\
\hline 12,16 & Gibbsiella dentisursi (AB566415) & 99.7 & Gammaproteobacteria \\
\hline 22 & Pseudomonas sp. (JQ522968) & 99.0 & Gammaproteobacteria \\
\hline $25,42,45,28$ & Klebsiella sp. (GU301269) & $99.6-99.8$ & Gammaproteobacteria \\
\hline $27,44,43,26$ & Klebsiella oxytoca (JF772070) & $99.4-99.8$ & Gammaproteobacteria \\
\hline 54,59 & Klebsiella sp. CPK (GU301269) & 99.6 & Gammaproteobacteria \\
\hline 57 & Klebsiella oxytoca (JX196648) & 99.2 & Gammaproteobacteria \\
\hline 29,46 & Enterobacter sp. JJDP1 (JQ726698) & 100 & Gammaproteobacteria \\
\hline 32 & Enterobacter sp. ZYXCA1 (JN107752) & 100 & Gammaproteobacteria \\
\hline 33 & Enterobacter sp. IICDBZ6 (JN836923) & 99.8 & Gammaproteobacteria \\
\hline 55 & Enterobacter ludwigii (KC139450) & 98.7 & Gammaproteobacteria \\
\hline 67 & Enterobacter sp. (JN129489) & 98.9 & Gammaproteobacteria \\
\hline 36 & Nevskia sp. (JQ710439) & 100 & Gammaproteobacteria \\
\hline 63 & Enterobacteriaceae bacterium (HM235485) & 99.8 & Gammaproteobacteria \\
\hline 65 & Buttiauxella sp. (JF281151) & 99.8 & Gammaproteobacteria \\
\hline 66 & Buttiauxella sp. (JX406856) & 99.8 & Gammaproteobacteria \\
\hline 4 & Methylobacterium sp. (FJ225120) & 100 & Alphaproteobacteria \\
\hline 5,38 & Methylobacterium populi (JQ660234) & $99.7-100$ & Alphaproteobacteria \\
\hline 39 & Brevundimonas sp. S2U9 (HE814668) & 100 & Alphaproteobacteria \\
\hline 40 & Sphingomonas sp. D40y (HE962513) & 100 & Alphaproteobacteria \\
\hline 6,8 & Enterococcus sp. (JF813181) & $99.0-100$ & Firmicutes \\
\hline 7 & Enterococcus gallinarum (JQ805717) & 100 & Firmicutes \\
\hline 9 & Enterococcus casseliflavus (JX035954) & 100 & Firmicutes \\
\hline 61 & Lysinibacillus sphaericus (JN377788) & 98.7 & Firmicutes \\
\hline 13,41 & Microbacterium sp. (EU584504) & 100 & Actinobacteria \\
\hline 30 & Uncultured bacterium (JN394024) & 99.8 & Unclassified \\
\hline 64 & Uncultured bacterium (GQ411142) & 99.6 & Unclassified \\
\hline 60 & Uncultured Chitinophaga sp. (KC110981) & 100 & Bacteroidetes \\
\hline 31 & Uncultured plastid (HM270514) & 100 & Eucariote plastid \\
\hline
\end{tabular}

the larvae fed on cambium, phloem, and xylem while the adults on foliage and tender bark. An analogous finding was observed in the case of another wood-boring beetle Agrilus planipennis [36], which was similar to Anoplophora in the complexity of the larval gut community [37].

The observed stability in the composition of the bacterial community at a high taxonomic level may indicate that the overall function of the community is achieved despite variations in its bacterial members. This may indicate that though most symbionts are environmentally-derived transient bacteria, at least some may play a key role in the physiology of this beetle. In particular, the dominance of Enterobacteriaceae and Gammaproteobacteria in both larval and adult forms suggests that they are a constant fraction 
of the gut bacterial community and may be beneficial to host fitness because of their various abilities to hydrolyze and ferment carbohydrates, catalyze nitrogen fixation, and produce vitamins and pheromones. It should be noted that this phylogenetic group of microorganisms has been commonly detected in the gut of diverse insect orders and host diet, with the exception of detritivorous, pollenivorous, and dead wood xylophagous insects [36]. In Anoplophora, such microorganisms might act as facultative mutualistic bacteria recurrently acquired during feeding by ingestion and possibly horizontally transmitted between individuals. In particular, the recurrent detection of the diazotrophs Enterobacter sp., Klebsiella sp., Raoultella sp., Rahnella sp., and S. maltophilia suggests that their contribution to beetle nitrogen requirements may be noteworthy [38], as observed in other insect orders [39]. In addition, considering that no obligate anaerobic bacteria were identified, facultative anaerobic bacteria may work as oxygen scavengers and could have a significant role in creating the microsite anaerobic conditions necessary to allow nitrogen fixation [34]. Members of the Enterobacteriaceae are also known to be involved in pheromone production; for example, common gut isolates in locusts, E. cloacae, K. pneumonia, and P. agglomerans, are responsible for the production of components of a locust cohesion pheromone [40].

Interestingly, the presence of Gammaproteobacteria and more generally the composition of bacterial communities, are rather similar in different xylophagous beetles and significantly distinguished from those of insects feeding on dead lignocellulose tissues, such as termites. The diet and, consequently, mechanisms of digestion evolved in the host, including those related to the host gut anatomy, are thought to play an important role in structuring the bacterial community [36]. In view of recent reports identifying a novel endogenous exo/endocellulase from $A$. malasiaca, together with the characteristic anatomy of this beetle which harbours a relatively small hindgut, it is likely that the bacterial community associated with Anoplophora spp. is more closely related to host fitness rather than being primarily involved in wood degradation, though several lignocellulose-degrading microbes can be harboured $[41,42]$. Considering the bacteria identified in this study, Pseudomonas putida, Kocuria, and Acinetobacter were previously shown to have lignin degradation activity [43, 44]; Bacillus, Paenibacillus, Staphylococcus (Firmicutes), Sphingomonas (Alfaproteobacteria), Ralstonia, Comamonas (Betaproteobacteria), Dyella ginsengisoli, Stenotrophomonas (Gammaproteobacteria), Kocuria, Brevibacterium (Actinobacteria), and Chryseobacterium (Bacteroidetes) were shown to have cellulose and/or aromatics degradation capabilities $[45,46]$. In addition to the bacterial lignocellulose-degrading activities, the nutrient-extracting capacities exerted by fungi strictly associated with the host are thought to contribute to host nutrition, as recently indicated by enzymatic proprieties of the A. glabripennis isolate $F$. solani [47]. Moreover, some of these bacteria with specific enzymatic degrading activities are thought to play important roles in the detoxification of plant compounds, production of metabolites against pathogens, and plant-insect interactions
$[46,48]$. For example, several bacterial genera affiliated to Actinobacteria, Gammaproteobacteria, Betaproteobacteria, and Firmicutes that are contained in the oral secretions of the bark beetle Dendroctonus rufipennis were demonstrated to significantly inhibit the growth of antagonistic fungi [49]. In particular, recent findings suggest that symbiotic associations between insects and Actinobacteria could play a crucial role in the protection of the insect host, or its nutritional resources, against parasitoids or predators [50]. In this study, various actinobacterial genera were detected, though they represented a small fraction of the microbiome associated with Anoplophora spp.; further research is necessary to elucidate their potential functions.

A preliminary characterization of the bacterial communities associated with testicles and eggs of Anoplophora chinensis, despite being limited by the low number of individuals analyzed, allowed us to obtain initial information regarding the microorganisms potentially associated with these organs. Taken together, the results showed that the same microbial species identified in the insect gut were present in these tissues. In accordance with a previous study, it is noteworthy to mention the occurrence of a Xanthomonadaceae family member associated with immature eggs that may be vertically transmitted from the mother to the offspring [51].

\section{Conclusions}

The bacterial gut community of $A$. chinensis is relatively diverse and this diversity is maintained throughout different life stages and geographic locations. The community does not appear to be primarily involved in lignocellulose degradation, but conservation of its members at high ranks suggests that these bacteria are beneficial to the host fitness and may contribute to insect nutrition, presumably by providing a fixed nitrogen source. Further studies are needed to elucidate the specific functions of gut-associated bacteria. Similarly, further investigation is necessary to clarify the role and mode of transmission of bacteria associated with the reproductive systems of Anoplophora spp.

\section{Acknowledgment}

This study was supported by the project "Anoplophora chinensis (Forster): nuove acquisizioni di biologia, fisiologia, diffusione e possibilità di contenimento-ANOCHI" by Regione Lombardia, Italy.

\section{References}

[1] R. J. Dillon and V. M. Dillon, "The gut bacteria of insects: nonpathogenic interactions," Annual Review of Entomology, vol. 49, pp. 71-92, 2004.

[2] J. A. Breznak and A. Brune, "Role of microorganisms in the digestion of lignocellulose by termites," Annual Review of Entomology, vol. 39, pp. 453-487, 1994.

[3] M. Ohkuma, "Termite symbiotic systems: efficient bio-recycling of lignocellulose," Applied Microbiology and Biotechnology, vol. 61, no. 1, pp. 1-9, 2003. 
[4] A. E. Douglas, "Nutritional interactions in insect-microbial symbioses: aphids and their symbiotic bacteria Buchnera," Annual Review of Entomology, vol. 43, pp. 17-37, 1998.

[5] S. Shigenobu, H. Watanabe, M. Hattori, Y. Sakaki, and H. Ishikawa, "Genome sequence of the endocellular bacterial symbiont of aphids Buchnera sp. APS," Nature, vol. 407, no. 6800, pp. 81-86, 2000.

[6] A. E. Douglas, "The microbial dimension in insect nutritional ecology," Functional Ecology, vol. 23, no. 1, pp. 38-47, 2009.

[7] E. Crotti, C. Damiani, M. Pajoro et al., "Asaia, a versatile acetic acid bacterial symbiont, capable of cross-colonizing insects of phylogenetically distant genera and orders," Environmental Microbiology, vol. 11, no. 12, pp. 3252-3264, 2009.

[8] C. Damiani, I. Ricci, E. Crotti et al., "Paternal transmission of symbiotic bacteria in malaria vectors," Current Biology, vol. 18, no. 23, pp. R1087-R1088, 2008.

[9] G. Favia, I. Ricci, C. Damiani et al., "Bacteria of the genus Asaia stably associate with Anopheles stephensi, an Asian malarial mosquito vector," Proceedings of the National Academy of Sciences of the United States of America, vol. 104, no. 21, pp. 9047-9051, 2007.

[10] E. Gonella, E. Crotti, A. Rizzi et al., "Horizontal transmission of the symbiotic bacterium Asaia sp. in the leafhopper Scaphoideus titanus Ball (Hemiptera: Cicadellidae)," BMC Microbiology, vol. 12, no. 1, article S4, 2012.

[11] R. Koga, X.-Y. Meng, T. Tsuchida, and T. Fukatsu, "Cellular mechanism for selective vertical transmission of an obligate insect symbiont at the bacteriocyte-embryo interface," Proceedings of the National Academy of Sciences of the United States of America, vol. 109, no. 20, pp. 1230-1237, 2012.

[12] E. Crotti, A. Balloi, C. Hamdi et al., "Microbial symbionts: a resource for the management of insect-related problems," Microbial Biotechnology, vol. 5, no. 3, pp. 307-317, 2012.

[13] I. Ricci, C. Damiani, P. Rossi et al., "Mosquito symbioses: from basic research to the paratransgenic control of mosquito-borne diseases," Journal of Applied Entomology, vol. 135, no. 7, pp. 487493, 2011.

[14] C. Hamdi, A. Balloi, J. Essanaa et al., "Gut microbiome dysbiosis and honeybee health," Journal of Applied Entomology, vol. 135, no. 7, pp. 524-533, 2011.

[15] M. Colombo and L. Limonta, "Anoplophora malasiaca Thomson (Coleoptera Cerambycidae Lamiinae Lamiini) in Europe," Bollettino di Zoologia Agraria e di Bachicoltura, no. 33, Ser. 2, pp. 65-68, 2001.

[16] R. A. Haack, F. Hérard, J. Sun, and J. J. Turgeon, "Managing invasive populations of asian longhorned beetle and citrus longhorned beetle: a worldwide perspective," Annual Review of Entomology, vol. 55, pp. 521-546, 2010.

[17] K. D. Klepzig, A. S. Adams, J. Handelsman, and K. F. Raffa, "Symbioses: a key driver of insect physiological processes, ecological interactions, evolutionary diversification, and impacts on humans," Environmental Entomology, vol. 38, no. 1, pp. 67-77, 2009.

[18] S. M. Geib, M. D. M. Jimenez-Gasco, J. E. Carlson, M. Tien, and K. Hoover, "Effect of host tree species on cellulase activity and bacterial community composition in the gut of larval asian longhorned beetle," Environmental Entomology, vol. 38, no. 3, pp. 686-699, 2009.

[19] P. D. Schloss, I. Delalibera Jr., J. Handelsman, and K. F. Raffa, "Bacteria associated with the guts of two wood-boring beetles: Anoplophora glabripennis and Saperda vestita (Cerambycidae)," Environmental Entomology, vol. 35, no. 3, pp. 625-629, 2006.
[20] E. D. Scully, K. Hoover, J. Carlson, M. Tien, and S. M. Geib, "Proteomic analysis of Fusarium solani isolated from the asian longhorned beetle, Anoplophora glabripennis," PLoS ONE, vol. 7, no. 4, Article ID e32990, 2012.

[21] C.-J. Chang, C. P. Wu, S.-C. Lu et al., "A novel exo-cellulase from white spotted longhorn beetle (Anoplophora malasiaca)," Insect Biochemistry and Molecular Biology, vol. 42, no. 9, pp. 629-636, 2012.

[22] V. A. Cavalcante and J. Dobereiner, "A new acid-tolerant nitrogen-fixing bacterium associated with sugarcane," Plant and Soil, vol. 108, no. 1, pp. 23-31, 1988.

[23] A. Rizzi, L. Panebianco, D. Giaccu, C. Sorlini, and D. Daffonchio, "Stability and recovery of maize DNA during food processing," Italian Journal of Food Science, vol. 15, no. 4, pp. 499-510, 2003.

[24] E. F. DeLong, "Archaea in coastal marine environments," Proceedings of the National Academy of Sciences of the United States of America, vol. 89, no. 12, pp. 5685-5689, 1992.

[25] J. Messing, "New M13 vectors for cloning," Methods in Enzymology, vol. 101, pp. 20-78, 1983.

[26] A. M. Sass, H. Sass, M. J. L. Coolen, H. Cypionka, and J. Overmann, "Microbial communities in the chemocline of a hypersaline deep-sea Basin (Urania Basin, Mediterranean Sea)," Applied and Environmental Microbiology, vol. 67, no. 12, pp. 5392-5402, 2001.

[27] E. Gonella, I. Negri, M. Marzorati et al., "Bacterial endosymbiont localization in Hyalesthes obsoletus, the insect vector of bois noir in Vitis vinifera," Applied and Environmental Microbiology, vol. 77, no. 4, pp. 1423-1435, 2011.

[28] N. Raddadi, E. Gonella, C. Camerota et al., ““Candidatus Liberibacter europaeus" sp. nov. that is associated with and transmitted by the psyllid Cacopsylla pyri apparently behaves as an endophyte rather than a pathogen," Environmental Microbiology, vol. 13, no. 2, pp. 414-426, 2011.

[29] G. Merlino, A. Rizzi, F. Villa et al., "Shifts of microbial community structure during anaerobic digestion of agro-industrial energetic crops and food industry byproducts," Journal of Chemical Technology and Biotechnology, vol. 87, no. 9, pp. 13021311, 2012.

[30] K. Tamura, D. Peterson, N. Peterson, G. Stecher, M. Nei, and S. Kumar, "MEGA5: Molecular evolutionary genetics analysis using maximum likelihood, evolutionary distance, and maximum parsimony methods," Molecular Biology and Evolution, vol. 28, no. 10, pp. 2731-2739, 2011.

[31] S. Grünwald, M. Pilhofer, and W. Höll, "Microbial associations in gut systems of wood- and bark-inhabiting longhorned beetles [Coleoptera: Cerambycidae]," Systematic and Applied Microbiology, vol. 33, no. 1, pp. 25-34, 2010.

[32] A. Vasanthakumar, I. Delalibera, J. Handelsman et al., "Characterization of gut-associated bacteria in larvae and adults of the southern pine beetle, Dendroctonus frontalis Zimmermann," Environmental Entomology, vol. 35, no. 6, pp. 1710-1717, 2006.

[33] H. Yilmaz, K. Sezen, H. Kati, and Z. Demirbağ, "The first study on the bacterial flora of the European spruce bark beetle, Dendroctonus micans (Coleoptera: Scolytidae)," Biologia, vol. 61, no. 6, pp. 679-686, 2006.

[34] J. Morales-Jiménez, G. Zúñiga, L. Villa-Tanaca, and C. Hernández-Rodríguez, "Bacterial community and nitrogen fixation in the red turpentine beetle, Dendroctonus valens LeConte (Coleoptera: Curculionidae: Scolytinae)," Microbial Ecology, vol. 58, no. 4, pp. 879-891, 2009. 
[35] J. Morales-Jiménez, G. Zúñiga, H. C. Ramírez-Saad, and C. Hernández-Rodríguez, "Gut-associated bacteria throught the life cycle of the bark beetle Dendroctonous rhizophagus Thomas and Bright (Curculionidae: Scolytinae) and their cellulolytic activities," Microbial Ecology, pp. 1-11, 2012.

[36] D. R. Colman, E. C. Toolson, and C. D. Takacs-Vesbach, "Do diet and taxonomy influence insect gut bacterial communities?" Molecular Ecology, vol. 21, no. 20, pp. 5124-5137, 2012.

[37] A. Vasanthakumar, J. O. Handelsman, P. D. Schloss, L. S. Bauer, and K. F. Raffa, "Gut microbiota of an invasive Subcortical Beetle, Agrilus planipennis fairmaire, across various life stages," Environmental Entomology, vol. 37, no. 5, pp. 1344-1353, 2008.

[38] J. B. Nardi, R. I. Mackie, and J. O. Dawson, "Could microbial symbionts of arthropod guts contribute significantly to nitrogen fixation in terrestrial ecosystems?" Journal of Insect Physiology, vol. 48, no. 8, pp. 751-763, 2002.

[39] A. Behar, B. Yuval, and E. Jurkevitch, "Enterobacteria-mediated nitrogen fixation in natural populations of the fruit fly Ceratitis capitata," Molecular Ecology, vol. 14, no. 9, pp. 2637-2643, 2005.

[40] R. Dillon and K. Charnley, "Mutualism between the desert locust Schistocerca gregaria and its gut microbiota," Research in Microbiology, vol. 153, no. 8, pp. 503-509, 2002.

[41] H. Watanabe and G. Tokuda, "Cellulolytic systems in insects," Annual Review of Entomology, vol. 55, pp. 609-632, 2010.

[42] C.-J. Chang, C. P. Wu, S.-C. Lu et al., "A novel exo-cellulase from white spotted longhorn beetle (Anoplophora malasiaca)," Insect Biochemistry and Molecular Biology, vol. 42, pp. 629-636, 2012.

[43] D. C. Kalyani, S. S. Phugare, U. U. Shedbalkar, and J. P. Jadhav, "Purification and characterization of a bacterial peroxidase from the isolated strain Pseudomonas sp. SUK1 and its application for textile dye decolorization," Annals of Microbiology, vol. 61, no. 3, pp. 483-491, 2011.

[44] G. K. Parshetti, S. Parshetti, D. C. Kalyani, R.-A. Doong, and S. P. Govindwar, "Industrial dye decolorizing lignin peroxidase from Kocuria rosea MTCC 1532," Annals of Microbiology, vol. 62, pp. 217-223, 2012.

[45] T. D. Bugg, M. Ahmad, E. M. Hardiman, and R. Singh, “The emerging role for bacteria in lignin degradation and bioproduct formation," Current Opinion in Biotechnology, vol. 22, no. 3, pp. 394-400, 2011.

[46] N. Calderon-Cortes, M. Quesada, H. Watanabe, H. CanoCamacho, and K. Oyama, "Endogenous plant cell wall digestion: a key mechanism in insect evolution," Annual Review of Ecology, Evolution, and Systematics, vol. 43, pp. 45-71, 2012.

[47] E. D. Scully, K. Hoover, J. Carlson, M. Tien, and S. M. Geib, "Proteomic analysis of Fusarium solani isolated from the asian longhorned beetle, Anoplophora glabripennis," PLoS ONE, vol. 7, no. 4, Article ID e32990, 2012.

[48] V. Popa, E. Déziel, R. Lavallée, E. Bauce, and C. Guertin, "The complex symbiotic relationships of bark beetles with microorganisms: a potential practical approach for biological control in forestry," Pest Management Science, vol. 68, no. 7, pp. 963-975, 2012.

[49] Y. J. Cardoza, K. D. Klepzig, and K. F. Raffa, "Bacteria in oral secretions of an endophytic insect inhibit antagonistic fungi," Ecological Entomology, vol. 31, no. 6, pp. 636-645, 2006.

[50] M. Kaltenpoth, "Actinobacteria as mutualists: general healthcare for insects?" Trends in Microbiology, vol. 17, no. 12, pp. 529$535,2009$.

[51] S. M. Geib, M. del Mar Jimenez-Gasco, J. E. Carlson, M. Tien, R. Jabbour, and K. Hoover, "Microbial community profiling to investigate transmission of bacteria between life stages of the wood-boring beetle, Anoplophora glabripennis," Microbial Ecology, vol. 58, no. 1, pp. 199-211, 2009. 

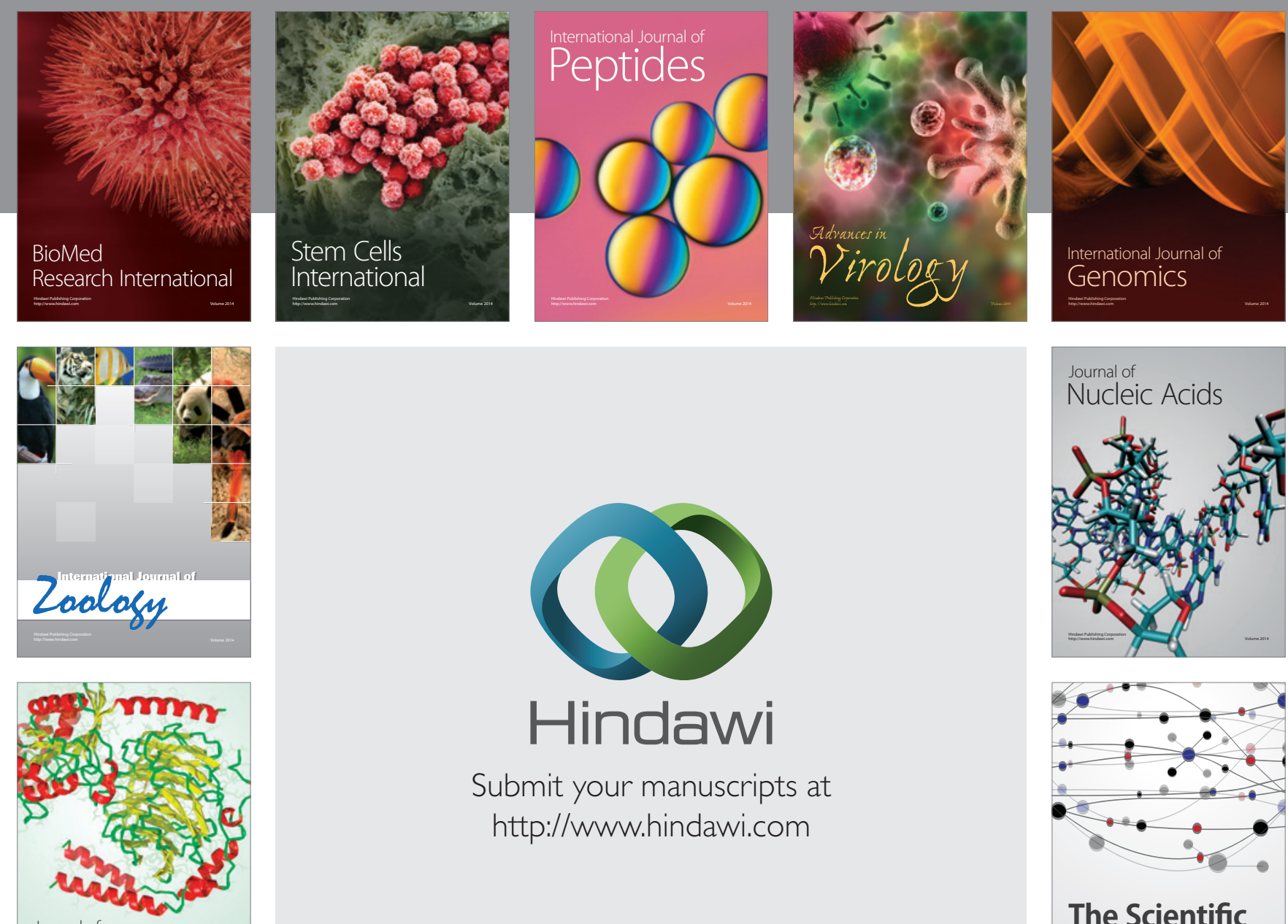

Submit your manuscripts at

http://www.hindawi.com

Journal of
Signal Transduction
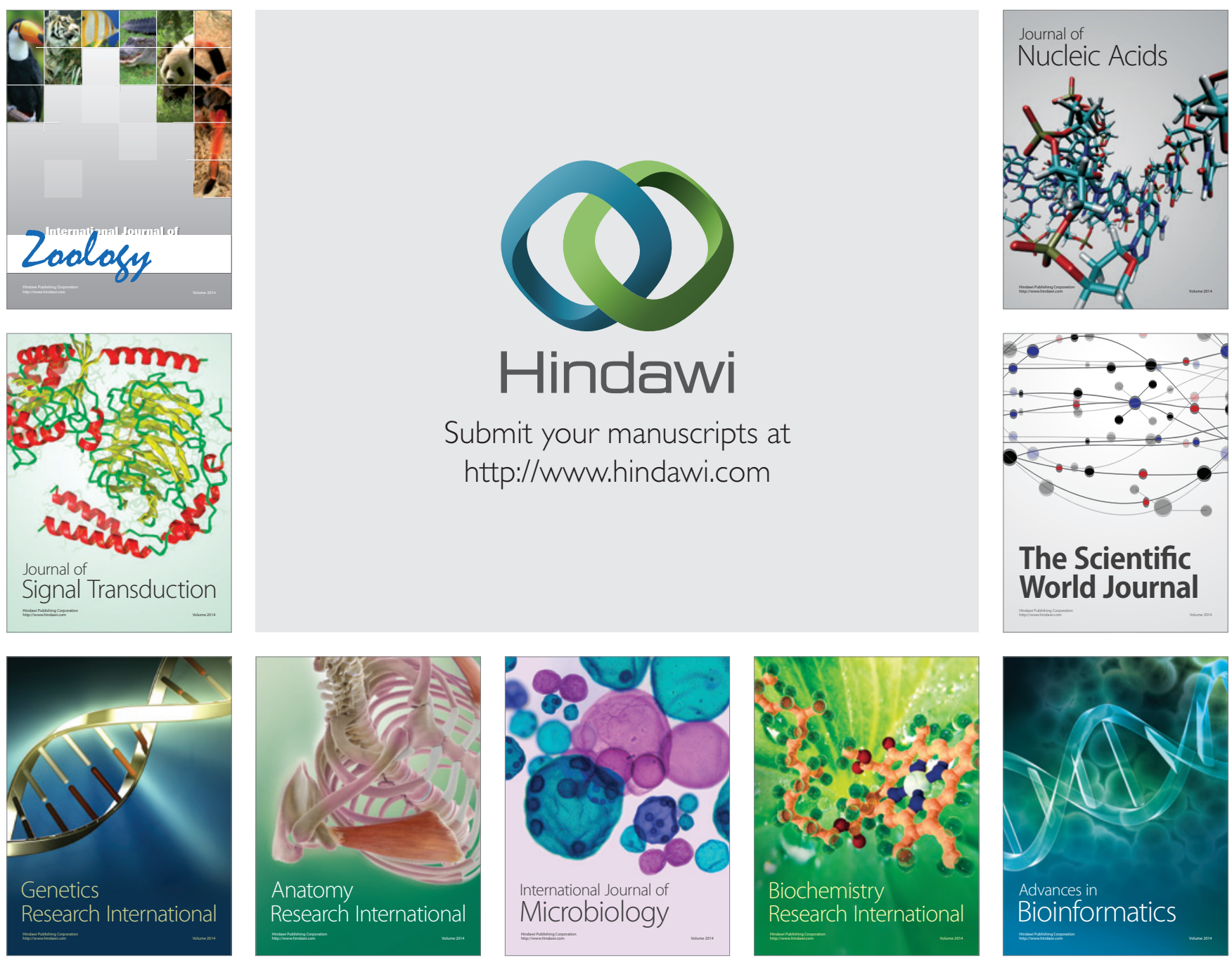

The Scientific World Journal
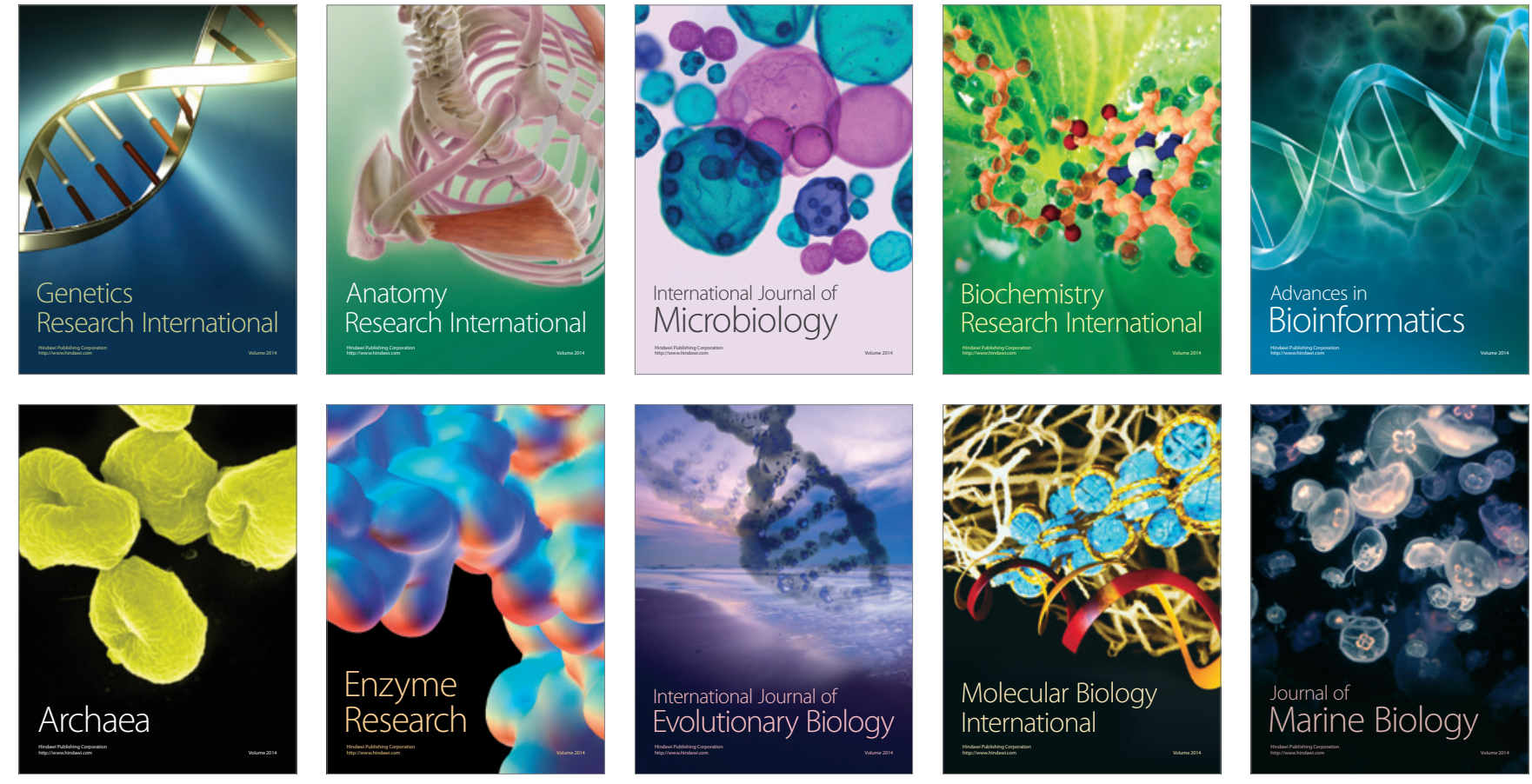